\title{
Neumología intervencionista: avances y perspectivas para el futuro
}

\section{Interventional pulmonology: advances and future perspectives}

LILIANA FERNÁNDEZ T., MD.

En décadas pasadas, gran cantidad de conceptos nuevos y desarrollos tecnológicos, transformaron la manera de practicar la neumología en general y la intervención en la vía aérea en particular.

Hoy, las indicaciones de broncoscopia incluyen la toma de muestras mínimamente invasivas de áreas distantes o complejas del parénquima pulmonar o el mediastino que van a procesarse hasta la extracción genómica y forman parte de la toma de decisiones en medicina personalizada y de precisión. Es también una herramienta muy útil en la evaluación $\mathrm{y}$ el manejo de lesiones benignas y malignas de la vía aérea central, en el tratamiento de pacientes ventilados en la unidad de cuidado intensivo, en el control de la hemoptisis severa, así como en la evaluación de los pacientes trasplantados. Ha incursionado, además, en el abordaje de la enfermedad pulmonar avanzada, caso del enfisema y el asma, mejorando la calidad de vida de quienes las padecen, y está cambiando la historia natural del cáncer en estados muy tempranos, con diagnósticos precisos y métodos terapéuticos novedosos, y en estados avanzados gracias a un manejo paliativo efectivo.
Todo lo anterior va de la mano con el desarrollo de programas mundiales de entrenamiento en neumología intervencionista que respaldan el trabajo multidisciplinario y la experticia en esta área.

Dentro de las nuevas tecnologías se cuenta con sistemas de adquisición de imágenes de alta definición y magnificación, que permiten evaluar, por medio de broncoscopia, el árbol traqueobronquial distal y las estructuras más allá de la pared bronquial; incluso, con algunos equipos modernos se pueden hacer "biopsias ópticas" y obtener imágenes histológicas adquiridas directamente con el broncoscopio, que incluye tomografía de coherencia óptica y microscopia fluorescente confocal con la idea de identificar lesiones preneoplásicas muy tempranas, infiltrar la pared, evaluar la compliance y dinámica alveolar durante ventilación mecánica, remodelar la pared en enfermedades obstructivas, entre otras. Cabe resaltar, no obstante, que todas estas técnicas necesitan estandarización en el futuro.

Otra tecnología fascinante en pleno desarrollo, es la navegación electromagnética, con la cual se genera un
Especialista en Medicina Interna. Subespecialista en Neumología. Neumología Intervencionista. Grupo de Investigación Biomédica en Tórax. Fundación Valle del Lili. Universidad ICESI, Facultad de Ciencias de la Salud. Cali, Colombia.

Correspondencia: Liliana Fernández Trujillo. Correo electrónico: lfernandez @)fcvl.org.

Recibido: 12/11/14, Aceptado: 10/12/14 
campo magnético alrededor del tórax del paciente y se obtienen imágenes tridimensionales en tiempo real, que guían con precisión al operador en el proceso de toma de muestras de lesiones distales a través del broncoscopio, inabordables en otra época, hecho con el que se mejora la sensibilidad de las biopsias transbronquiales, sirviendo para la ubicación en radiocirugía estereotáxica y marcando lesiones previa videotoracoscopia. A través de este método de guía, se pueden ubicar los catéteres mediante endoscopia para radiofrecuencia y microondas.

Ahora bien, de la mano con las imágenes se han desarrollado instrumentos más versátiles para la toma de muestras y el manejo de lesiones, incluyendo tecnología láser, electrocoagulación, argón plasma y criosondas que en combinación con las técnicas de broncoscopia flexible y rígida permiten un mejor manejo de la vía aérea compleja. Se cuenta, adicionalmente, con elementos como válvulas, coils, sellantes poliméricos, stent de diferentes clases que incluso ya pueden ser diseñados para cada caso en particular, catéteres de termoplastia, termocoagulación y braquiterapia para intervenir la vía aérea en enfermedades de difícil manejo.
Así pues, el futuro de la Neumología intervencionista está determinado no solo por la gran cantidad de innovaciones tecnológicas sino por el desarrollo de programas sólidos de entrenamiento para especialistas en esta disciplina que usen las nuevas tecnologías de manera coherente en beneficio del paciente.

La práctica de esta disciplina requiere un entendimiento profundo de la anatomía y fisiología del tórax así como también destreza, competencia, juicio clínico y acople con grupos multidisciplinarios que trabajan en pro un mejor resultado clínico y terapéutico.

En este número se presentan revisiones, casos y series de casos clínicos que reflejan nuestra experiencia y práctica en el campo de la neumología intervencionista en Colombia y América.

\section{Bibliografía}

1. Beamis JF, Mathur PM. Interventional pulmonology: current status and future direction. Respir Med. 2013;10:3-14.

2. Musani AL, Gasparini S. Advances and future directions in interventional pulmonology. Clin Chest Med. 2013;34:605-10.

3. Panchabhai TS, Mehta AC. Historical perspectives of bronchoscopy, connecting the dots. Ann Am Thorac Soc. 2015; 12(5):631-41. 